\title{
PAIS DE ALUNOS E EDUCADORES: UMA PARCERIA QUE PODE DAR CERTO
}

\section{PARENTS OF STUDENTS AND EDUCATORS: A PARTNERSHIP THAT CAN GIVE RIGHT}

\author{
Rosa Maria Alves da Silva (UNITOLEDO/ Araçatuba) \\ Maria Ângela Somaio Teixeira (UNIESP/Fag)
}

\begin{abstract}
Resumo: A presente investigação objetiva analisar as dificuldades apresentadas no processo de docência junto a alunos do curso de graduação em Pedagogia, oportunizando uma maior articulação teoria x prática. Após depoimentos dos docentes, observou-se que a situação das famílias contemporâneas já não é mais a mesma de antigamente, o que acarreta algumas dificuldades no ensino/aprendizagem. Assim, resolveu-se ouvir pais de crianças do ensino infantil e fundamental em três cidades da região de Araçatuba, visando a levantar dados que pudessem indiciar um conhecimento melhor do que pensam os pais sobre a situação, para se proceder a análise das causas de um possível distanciamento da vida escolar de seus filhos. Seguindo um roteiro prédeterminado de entrevistas, foi possível entender as condições sociais em que se encontram as famílias e obter dos pais opiniões sobre a escola, bem como de sua atuação e participação no processo ensino/aprendizagem. Dentre os resultados obtidos, o mais surpreendente foi o fato de que os pais têm um olhar favorável em relação à escola. Após análise dos dados coletados, atentou-se para novas formas de organização da estrutura familiar, assim como as limitações das escolas e dos profissionais que nela atuam para atender esse novo modelo de família.
\end{abstract}

Palavras-chave: Educação. Escola. Família. Parceria

\begin{abstract}
This research aims to analyze the difficulties encountered in the process of teaching with the students of graduate degrees in education, providing opportunities for greater integration of theory $\mathrm{x}$ practice. After testimonials from teachers, it was observed that the situation of contemporary families is no longer the same as before, which caused some difficulties in teaching and learning. So, we decided to listen to parents of children in kindergarten and elementary education in three cities in the Araçatuba region, aimed at providing data that could indicate a better understanding of what parents think about the situation, to undertake an analysis of causes of possible separation from their children's school life. Following a pre-determined amount of interviews, it was possible to understand the social conditions in which they are the families and get parents' opinions about the school, as well as their performance and participation in the teaching / learning. Among the results, the most surprising was the fact that parents have a look favorable in relation to school. After analyzing the collected data, looked forward to new ways of organizing the family structure as well as the limitations of schools and professionals working in it to meet this new family model.
\end{abstract}

Keywords: Education School. Family. Partnership. 


\section{Introdução}

A pesquisa explicitada neste artigo não teve, a princípio, a intenção de tornar-se um trabalho de natureza científica, foi se constituindo como tal durante o processo de desenvolvimento. A princípio, caracterizou-se como uma estratégia de ensino da disciplina de Didática de dois cursos de Pedagogia que objetivava detectar as maiores dificuldades que docentes atuantes na Educação Infantil e nas séries iniciais do Ensino Fundamental sentem no ato de ensinar e posteriormente buscar explicações nas diversas teorias possíveis. A partir da análise dos dados coletados, sentiu-se a necessidade de estender a investigação a pais de alunos e diante da relevância das respostas obtidas nessa segunda investigação, resolveu-se organizar, aprofundar e sistematizar o estudo.

A pesquisa realizada com os professores consistiu numa entrevista a 160 docentes com base na seguinte pergunta: "Quais são as duas maiores dificuldades que você tem no exercício da docência?" Diante das respostas coletadas, o que motivou a continuidade da pesquisa foi o fato de que $48 \%$ das respostas obtidas indiciavam a falta de apoio dos pais em relação ao trabalho desenvolvido na Escola e $40 \%$ apontavam a indisciplina dos alunos.

Considerando que a indisciplina é um fator que nos remete diretamente à família, já que o ato de educar é uma função historicamente atribuída a ela, pode-se concluir que praticamente $90 \%$ dos fatores, que na concepção dos professores, constituem-se em dificuldades de ensino, referem-se aos alunos e a seus pais, excluindo seus responsáveis do processo de ensino, ou seja, do sistema escolar, desde sua estrutura e organização, passando pelas concepções e princípios até as questões metodológicas.

Diante desse quadro e considerando a porcentagem significativa que o compôs, o que lhe confere um grau de suma importância, resolveu-se elaborar uma investigação junto aos pais, visando a levantar dados que pudessem indiciar um conhecimento melhor da situação apontada pelos professores. Mediante as entrevistas, seguindo um roteiro pré-determinado, contendo questões fechadas (05) e abertas (04), foi possível entender as condições sociais em que se encontram as famílias e obter dos pais opiniões que têm sobre a escola, bem como de sua atuação e participação no processo de aprendizagem de seus filhos. A expectativa era a de que, entendendo-se melhor a dinâmica das famílias na sociedade atual, seria possível pensar-se em formas mais apropriadas de aproximação entre as duas agências educacionais.

\section{E os pais, o que dizem?}

A pesquisa ora apresentada foi realizada com 350 pais de três cidades da região noroeste do Estado de São Paulo com idades variadas entre 20 a 40 anos, predominando a faixa etária entre 31 a 40 anos. A grande maioria, 80\% dos filhos destes, estuda em escolas públicas, sendo que 20\% frequentam a Educação Infantil, 50\% nas séries iniciais do ensino fundamental e os demais nas séries finais e no Ensino médio. Como apenas $4 \%$ dos filhos dos pais entrevistados estão no ensino superior, trabalhou-se com uma amostragem de pais jovens, com filhos novos e que necessitam de um acompanhamento mais constante por parte dos responsáveis.

A primeira constatação considerada significativa refere-se ao número de filhos das famílias entrevistadas: $25 \%$ possuem apenas 1 filho; $33 \%, 2$ filhos e somente $4 \%$ possuem 4 ou mais filhos. Esse fato demonstra que a organização e a estrutura das 
famílias, na atualidade, estão se modificando, entre outras variáveis, no que se refere ao número de componentes. Talvez esse fato indicie certa preocupação com as possibilidades educativas que se apresentam a essas famílias. Reduzir o número de filhos parece garantir melhores condições financeiras e, consequentemente, melhores condições de vida.

Segundo Tedesco (2001, p. 31-32), num processo de socialização distinguemse dois elementos distintos: a socialização primária, que normalmente se dá no seio da família, a fase em que o indivíduo está na infância e mediante a qual se transforma em membro da sociedade; é a mais importante para o indivíduo, pois por meio dela, adquire a linguagem, os esquemas básicos de interpretação da realidade e os rudimentos do aparato legitimador.

As duas características mais importantes da socialização primária são a carga afetiva e a identificação absoluta com o mundo, tal como os adultos o apresentam. Nesse sentido, é importante perceber que a socialização primária implica mais do que uma aprendizagem puramente cognitiva. Ela se realiza em circunstâncias de enorme carga emocional. Já a socialização secundária é todo o processo posterior, que incorpora o indivíduo já socializado a novos setores do mundo objetivo de sua sociedade.

$\mathrm{Na}$ sociedade atual, os conteúdos da socialização primária são transmitidos com uma carga afetiva diferente da do passado. Os grupos e as opções às quais uma criança é exposta tendem a diferenciar-se, a multiplicar-se e a modificar-se com uma velocidade sem precedentes. Percebe-se, assim, uma evolução nas relações familiares que trouxeram como consequências uma variação na composição e no funcionamento da família: a incorporação da mulher no mercado de trabalho, a tendência a reduzir o número de filhos, o aumento das separações e do número de filhos que vivem sozinhos ou com um dos pais; produz-se uma diminuição do tempo real que os adultos significativos passam com seus filhos; esse tempo é agora ocupado por outras instituições - escolas, creches etc., ou pela exposição a meios de comunicação (quando a criança está só diante das mensagens que recebe). Os adultos significativos para a formação das novas gerações tendem a diferenciar-se. O ingresso nas instituições é cada vez mais precoce, pois os adultos perderam a segurança e a capacidade de definir o que querem oferecer como modelo às novas gerações.

Outro dado extremamente relevante para os propósitos desta pesquisa é o fato de que a ocupação profissional ocupa um grande espaço de tempo na vida desses pais, o que tem implicações no relacionamento com os filhos e no acompanhamento de suas atividades, incluindo a educação escolar: $65 \%$ das mães entrevistadas exercem atividades profissionais fora de casa e a média diária de trabalho delas é de 8 horas; $82 \%$ dos pais entrevistados exercem atividades profissionais com uma média diária de 10 a 12 horas.

$\mathrm{O}$ fato de terem uma jornada de trabalho tão intensa agrava-se ainda mais se considerarmos que, ao chegar em casa, os pais e, principalmente, as mães têm os afazeres domésticos para fazer, o que limita ainda mais o tempo que poderiam dedicar aos cuidados e educação dos filhos, como atesta o seguinte depoimento de uma mãe ao ser interrogada sobre sua participação na vida escolar do filho "Só não participo com mais frequência devido trabalhar fora e ficar $8 h 48 m$ fora de casa [...]."

Acrescente-se a isso outro fator que está se tornando mais frequente na atualidade. Muitos pais que não estudaram enquanto jovens, voltam à escola no período 
noturno, pensando até mesmo na melhoria futura das condições de vida da família, mesmo que para isso tenham que sacrificar ainda mais o relacionamento presente com os filhos, "Não vou às reuniões porque estudo à noite, porque quero dar o melhor para meu filho."

Essa escassez de tempo é responsável, em parte, pela transferência de parte das funções educacionais que historicamente eram de responsabilidade da família para as escolas, o que é ressentido e, por vezes, mal entendido pelos profissionais da escola, como atesta o seguinte depoimento de um professor: "[..] hoje se trabalha muito $e$ alguns pais acham que é a escola que tem obrigação de educar seus filhos e eles (os pais) não precisam se preocupar. Acredito que falta muito ainda por parte dos pais[...]."

Jussara Hoffman ( 2001, p.34 ), ao se referir à participação das famílias, na escola,como alternativa para que as crianças aprendam com qualidade e são sejam excluídas, afirma:

Os pais devem participar da escolaridade de seus filhos, considerando, entretanto, a natureza do envolvimento; a realidade social destes pais; a constituição de suas famílias; a luta pela sobrevivência etc., nos faz ponderar que as dificuldades de aprendizagem dos alunos não podem ser atribuídas às famílias, muito menos o trabalho de superação destas dificuldades não pode recair sob a responsabilidade destes, mas dos profissionais que atuam nas escolas, bem como são de sua responsabilidade a aquisição de atitudes e habilidades que favoreçam o enriquecimento das relações interpessoais no ambiente escolar.

Acompanhar o processo vivido pelos filhos, dialogar com a escola, assumir o que lhes é de responsabilidade é compromisso dos pais. Promover o diálogo entre os pais e os professores é função da escola, que não significa atribuir a eles a tarefa da escola. Outro fator que dificulta um apoio maior dos pais em relação à vida escolar dos filhos é a condição de nenhuma ou pouca escolaridade deles o que impede, por exemplo uma colaboração maior na execução das tarefas escolares: "Não consigo ensinar meu filho porque sou analfabeta. Muitos pais não conseguem ajudar seus filhos com as tarefas porque não sabem." "O ensino está bom. O problema é que os professores dão muita matéria e muita tarefa, às vezes, os alunos nem sabem porque estão copiando. Muitos pais não conseguem ajudar os filhos com a tarefa porque não sabem". "Os professores não querem ensinar e passam a responsabilidade para os pais"

Embora se saiba que o uso da lição de casa proporcione oportunidade de aprofundar o entendimento e as habilidades relativas ao conteúdo apresentado, essa prática, não razas vezes, pode constituir-se em desentendimentos entre escola e pais. Controvérsias e desencontros têm ocorrido por conta de vários enfoques da lição de casa, tais como: os professores alegam que os pais devem ajudar os filhos em casa, que são desinteressados, que empurram para a escola tudo o que não fazem; enquanto que as mães acham que ensinar é uma atribuição dos professores. Discordam em relação à complexidade das tarefas, alegando que são tão difíceis que não estão ao alcance nem das crianças, nem de sua família.

Essa situação provoca um grande transtorno nas relações cotidianas das famílias que acabam por desistir de acompanhar a vida escolar dos filhos. Nesse sentido, Marzano, Pickering e Pollock (2008, p.74-78), ao abordar esse tema, apresentam quatro generalizações que podem guiar os professores no uso da lição de casa. 
1.quantidade de lição de casa designada aos alunos, dos diferentes níveis do ensino fundamental e do ensino médio, deve ser diferente. Nas séries iniciais, o desempenho dos alunos é menor em relação aos alunos de ensino médio; 2. o envolvimento dos pais na lição de casa deve ser mantido no mínimo possível; ou seja, os pais não devem 'facilitar' a lição de casa;

3. o propósito da lição de casa deve ser identificado e articulado: o propósito da lição de casa deve ser identificado e articulado, cujos propósitos tem por finalidade treinar uma atividade com a qual o aluno já tenha familiaridade; preparar o aluno para um novo conteúdo que será oportunamente apresentado e trabalhado;

4. se a lição de casa foi designada, ela deve ser comentada; deve ser medida em conceitos e anotada pelo professor.

Portanto, i professor deve estabelecer uma política de comunicação de lição de casa para evitar tensão entre pais, alunos e professores. Deve também planejar lições de casa que articulem claramente o propósito e o resultado. Deve também variar as abordagens para proporcionar feedback.

Questionados sobre a atuação das escolas de seus filhos, os pais demonstraram apreço pelo trabalho desenvolvido nelas e reconhecem a sua importância no desenvolvimento integral dos filhos e uma promessa de emancipação social: $25 \%$ dos pais consideraram o trabalho da escola de seus filhos como ótimo e 35\% como bom.

- A proposta de ensino é ótima

- Os professores são capacitados e atenciosos

- A escola tem a estrutura necessária

- O material fornecido pela escola é bom

- Meu filho está lendo e escrevendo

- Meu filho tem desempenho significativo

- A criança aprende a raciocinar e analisar

Outro dado interessante é que alguns pais entrevistados souberam apontar de forma clara os problemas que percebem no trabalho das Escolas:

- O ensino é tradicional para os dias de hoje

- A escola faz poucas reuniões

- A escola fornece poucas informações sobre o trabalho que desenvolve

- É dificil falar com a professora fora das reuniões

- Deveria voltar ao ensino tradicional, há muita cópia, exige-se muito e não ensina nada.

- Deveria haver menos alunos em sala de aula.

- O ensino é difícil. Na primeira série, o aluno tem 3 livros e ainda não sabe ler.

Questionados sobre as dificuldades dos próprios filhos no processo ensino/aprendizagem, embora $37 \%$ dos pais terem alegado que os filhos não têm dificuldades, os demais as indicaram até de forma bastante específica, como:

- Leitura e escrita- $20 \%$

- Matemática- 6\% 
- Caligrafia difícil- $2,5 \%$

- Falta de interesse $-20 \%$

- Indisciplina de outros alunos- $8 \%$

- Memorização- $1 \%$

Essa constatação parece indicar que os pais não estão tão afastados da vida escolar dos filhos como pode parecer. $\mathrm{O}$ mundo pós-moderno legou-nos, à parte tantas conquistas tecnológicas, científicas e culturais, uma herança bastante negativa no que diz respeito às relações humanas, à inteligência emocional e à harmonização planetária. No campo cognitivo, nota-se um descompasso, na medida em que o acesso ao conhecimento não se dá de maneira democrática.

Torna-se cada vez mais clara a evidência do empobrecimento de valores, a escassez da ética, do avanço célere da corrupção e da violência, do poder do capitalismo selvagem e principalmente do caos em que se transformou a vida social, na atualidade. Tal estado de coisas provocou um desnorteio sem tamanho, em especial em nossas crianças e jovens que convivem com total falta de referências positivas que possam garantir-lhes uma vida digna, preceito primeiro da Declaração dos Direitos do Homem, proclamado em 1948. Ao se constatar essa situação tão grave, indaga-se: "-O que fazer? - Como vencer esses obstáculos? - Quem poderá ajudar na superação dessa problemática? Esses questionamentos apontam para a um novo olhar sobre a educação que temos hoje e dos responsáveis por ela.

Embora a Constituição Federal de 1988, em seu artigo 205, deixe clara a parceria: Estado, família e sociedade como obrigatória no processo de formação das futuras gerações, na prática, constata-se uma série de obstáculos a esse grande desafio que se tornou a educação do atual milênio. A família encontra sérias dificuldades em educar seus filhos, não se achando preparada para as exigências da vida moderna. A escola, por sua vez, não consegue dar conta de acompanhar com êxito as transformações do mundo, nem mesmo assumir funções que outrora pertenciam, primeiramente, à família, vendo desmoronar o pacto educativo necessário ao enfrentamento dos desafios de educar. Estabece-se um fosso, cada vez mais profundo entre escola e família, com expectativas e exigências de ambos os lados, dificultando as relações para uma cooperação coletiva entre ambas instituições.

Ao abordar o compromisso dos educadores com a comunidade, Contreras (2202, p.28) argumenta que "A educação não é um problema da vida privada dos professores, mas uma ocupação socialmente encomendada e responsabilizada publicamente". É também necessário entender que a responsabilidade pública envolve a comunidade na participação das decisões sobre o ensino. Se a educação for entendida como um assunto que não se reduz apenas às salas de aula, mas que tem uma clara dimensão social e política, a profissionalidade pode significar uma análise e uma forma de intervir nos problemas sociopolíticos que competem ao trabalho de ensinar.

A presente pesquisa demonstrou que a participação dos pais na vida escolar é ainda incipiente. A grande maioria dos pais entrevistados, 82\% responderam afirmativamente sobre sua participação na escola. Argumentados, porém, sobre as formas de fazê-lo, citam a frequência às reuniões e acompanhamento das tarefas de casa, quando possível, desconhecendo outras formas efetivas de participação.

Outro fator a se considerar é o que se refere ao tipo e a intensidade de encontros entre a família e a escola. Reduzir esse espaço de integração somente às 
reuniões de Pais e Mestres, ocorridas em três ou quatro ocasiões anuais é empobrecer demais as possibilidades de uma parceria bem sucedida. A própria organização dessas reuniões, sem pauta que favoreça um acolhimento, recheada de ocasiões onde se apontam os aspectos negativos do desempenho escolar dos filhos, faz com que os pais sintam-se culpados, envergonhados, tímidos e impotentes para apresentar qualquer solução para os problemas levantados. Em contrapartida, os professores já rotulam os pais de desinteressados, ausentes e descompromissados com a escola.

O compromisso social da prática docente pressupõe uma visão social ampla que faz do educador alguém sensível ao trabalho que realiza, ao contexto em que está inserido, e à responsabilidade de provocar um estreitamento de laços com a comunidade a que pertence, em especial à família do educando, bem como a certeza de saber que não poderá realizar a contento uma educação de qualidade sem essa aproximação. Cabe, pois, à Escola, na situação relatada acima, tomar a iniciativa de inserir os pais, de forma mais efetiva, na gestão escolar.

Uma ação coletiva e organizada faz-se necessário nessa empreitada. Essa deveria ser uma das mais importantes metas a ser apontada no Projeto Político Pedagógico das unidades escolares, com perseguição contínua de seu desenvolvimento e avanço. Abranges (2003, p.78-94) considera a gestão da educação um aprendizado para a comunidade, e, nesse sentido, os órgãos colegiados possibilitam a implementação de novas formas de gestão por meio de um modelo de administração coletiva em que todos participam dos processos decisórios no acompanhamento, execução e avaliação das ações das unidades escolares. A gestão colegiada proporciona uma transformação da concepção de escola, para todos os envolvidos: professores, direção, funcionários, alunos, pais e moradores da comunidade.

A referida autora faz, ainda, uma análise interessante sobre o colegiado. Nas entrevistas com membros desses órgãos e experiências de escolas públicas mineiras retirou dados e transformou-os em categorias, divididas em três temas básicos: as concepções e avaliações a respeito da descentralização e dos órgãos colegiados, bem como as propostas e estratégias para sua concretização; a participação dos pais representantes da comunidade na gestão colegiada, suas posições mediante o trabalho coletivo e a identificação de suas respostas ao serem chamados para gerenciar as decisões públicas na educação; o aprendizado político adquirido pelos representantes da comunidade no processo participativo, especificando como ele se dá e qual o tipo de aprendizado eles absorvem e constroem ao longo dessa experiência.

Ao concluir o trabalho salienta, ainda, que a garantia da presença dos pais nas decisões, já tem provocado certas mudanças, apesar dos problemas da falta de preparação para serem atores de um processo, ao qual não estão habituados. O interesse por parte dos pais aumentou, com uma participação mais ativa, nas atividades da escola, permitindo-lhes dividir responsabilidades e propiciar maior contato com os pais. A participação ativa leva os pais a assumirem um compromisso real com a escola e quando isso acontece fica imensamente facilitada a parceria. Portanto, incentivar e abrir um espaço para essa participação é condição sine qua non para se avançar em busca de uma integração entre pais e escola.

Embora seja clara a interdependência escola/família no ato de educar, as relações entre ambas as instituições não se dão de forma harmoniosa. Assim se manifestam Delors e Eufrázio (1998, p.65), pois segundo esses autores, 
As relações da família com o sistema educativo são, por vezes, tidas como relações de antagonismo: em alguns países em desenvolvimento, os saberes transmitidos pela escola podem opor-se aos valores tradicionais da família; acontece também que as famílias mais desfavorecidas encaram, muitas vezes, a instituição escolar como um mundo estranho de que não compreendem nem os códigos nem as práticas.

Um diálogo entre pais e professores é, pois, indispensável, porque o desenvolvimento adequado das crianças implica uma complementaridade entre educação escolar e educação familiar. As experiências de educação pré-escolar dirigidas a populações desfavorecidas mostraram que a sua eficácia deveu-se muito ao fato das famílias terem passado a conhecer melhor e a respeitar mais o sistema escolar e viceversa, isto é, quando os professores estreitaram os laços de relacionamento com as crianças e suas famílias, conhecendo-lhes suas histórias de vida, suas dificuldades, e os obstáculos de aproximação.

Sustentam, ainda, os autores referidos que cada um aprende ao longo de toda a sua vida no seio do espaço social constituído pela comunidade a que pertence. Esta varia, por definição, não só de um indivíduo para outro, mas também no decurso da vida de cada um. A educação deriva da vontade de viver juntos e da coesão do grupo.

\section{Considerações finais}

Diante do exposto, podemos afirmar que temos novas formas de organização da estrutura familiar e que a escola não está preparada para enfrentar esse novo modelo de família. Assim, verifica-se limitações das escolas e dos profissionais que nela atuam para atender as crianças que adentram hoje na escola do século XXI.

Para isso, seria necessário uma compreensão ampla e real das dificuldades a que estão sujeitas as famílias, pois estas se defrontam com múltiplas obrigações, conflitos familiares e profissionais, sem tempo para si, a preocupação com a subsistência não dá margem nem para sua própria formação. É preciso que enxerguemos essa nova realidade, que não é a mesma de outrora, assim seria possível ajudar a derrubar o muro que ora se instalou impedindo um convívio e uma cooperação mais profícua em prol da educação de nossas crianças e jovens.

\section{Referências Bibliográficas}

CONTRERAS, José. A autonomia dos professores. São Paulo: Cortez, 2002

DELORS, Jacques; EUFRÁZIO, José Carlos. Educação: um tesouro a descobrir. São Paulo: Cortez, 1998.

HOFFMAN, Jussara. Avaliar para promover: as setas do caminho. Porto Alegre: Mediação, 2001.

MARZANO, Robert J.; PICKERING, Debora J.; POLLOCK, Jane E. Ensino que funciona: estratégias baseadas em evidências para melhorar o desempenho dos alunos. Porto Alegre: Artmed, 2008.

TEDESCO, Juan Carlos. O novo pacto educativo. São Paulo: Ática, 2001. 